\title{
Demanda energética de uma semeadora-adubadora em diferentes velocidades de deslocamento e rotações do motor ${ }^{1}$
}

\author{
Energy needs of a planter at different travel and engine speeds
}

\author{
João Cleber Modernel da Silveira ${ }^{2 *}$, Haroldo Carlos Fernandes ${ }^{3}$, Alcir José Modolo ${ }^{4}$, Suedêmio de Lima Silva ${ }^{5}$ \\ Emerson Trogello
}

\begin{abstract}
RESUMO - A velocidade de operação do trator influencia diversos aspectos, entre eles o consumo de combustível, a capacidade operacional e a qualidade de semeadura. Este trabalho teve como objetivo avaliar a demanda energética de um conjunto tratorsemeadora-adubadora em sistema plantio direto, em função das velocidades de deslocamento e rotações no eixo do motor, na semeadura da cultura do milho. Os 12 tratamentos foram constituídos de quatro velocidades de deslocamento, obtidas em função dos escalonamentos de marchas e de três rotações do motor do trator. Durante a semeadura, monitoraram-se a velocidade de operação, a rotação do motor, a força de tração e o consumo horário de combustível. Os resultados mostraram que o requerimento de potência na barra de tração, média, por linha de semeadura, por profundidade do sulco e por área mobilizada aumentou com o aumento da velocidade de operação do conjunto mecanizado. O consumo horário de combustível foi elevado com o aumento da velocidade de operação e da rotação do motor, sendo menor na rotação do motor de $1.500 \mathrm{rpm}$.
\end{abstract}

Palavras-chave: Desempenho operacional. Mecanização. Plantio direto.

\begin{abstract}
The operating speed of the tractor influences various aspects, including fuel consumption, operational capacity and sowing quality. This study aimed to assess the energy needs of a tractor-planter when sowing maize in a no-tillage system, according to its travel speed and the rotation speed of the motor shaft. The 12 treatments consisted of four travel speeds, obtained by staggering the gears, and three tractor-engine rotation speeds. During sowing, the speed of operation, engine speed, the traction force and hourly consumption of fuel were monitored. The results showed that the average power requirement on the drawbar per seeding row, groove depth, and worked area, increased with an increase in the operating speeds of the mechanism. Hourly fuel consumption went up with the increase in operating and engine-rotation speeds, being lowest at a speed of 1,500 rpm.
\end{abstract}

Key words: Operational performance. Mechanization. No-tillage.

\footnotetext{
*Autor para correspondência

${ }^{1}$ Recebido para publicação em 10/08/2011; aprovado em 23/04/2012

Parte da Tese de Doutorado do primeiro autor, pesquisa financiamenta pelo CNPq

${ }^{2}$ Instituto Federal de Educação, Ciência e Tecnologia Goiano/IF Goiano, Campus Rio Verde-GO, Rodovia Sul Goiana, Km 01 s/n, Zona Rural, Caixa Postal 66, Rio Verde-GO, Brasil, 75.901-970, jcmodernel@yahoo.com.br

${ }^{3}$ Departamento de Engenharia Agrícola/Universidade Federal de Viçosa/UFV, Viçosa-MG, Brasil, 36.570-000, haroldo@ufv.br

${ }^{4}$ Coordenação do Curso de Agronomia, Universidade Tecnológica Federal do Paraná, Pato Branco-PR, Brasil, alcir@utfpr.edu.br, etrogello@yahoo.com.br

${ }^{5}$ Departamento de Ciências Ambientais e Tecnológicas/Universidade Federal Rural do Semi-Árido, Mossoró-RN, Brasil, suedemio@ufersa.edu.br
} 


\section{INTRODUÇÃO}

Com a necessidade cada vez maior de produção de alimentos, vários sistemas de produção agrícola vêm sendo desenvolvidos pelo homem, sendo que alguns vêm esgotando e empobrecendo os solos, pois estão sendo usados de maneira inadequada. Por essa razão, tem-se buscado o uso de sistemas para a conservação do solo, entre eles a semeadura direta. Entretanto, as semeadoras utilizadas nesse sistema de produção sofreram alterações em todo seu processo de fabricação, tornando-as robustas, pesadas e com órgãos ativos de ataque ao solo capazes de romper camadas compactadas de solo ocasionadas pelo intenso tráfego de máquinas, passando a exigir tratores com maior potência para tracioná-las.

Oliveira et al. (2000) relatam que houve grande evolução das semeadoras-adubadoras utilizadas nesse sistema, principalmente quanto à sua concepção e utilização, sendo que as principais mudanças ocorreram nos mecanismos de distribuição de fertilizantes, os quais eram constituídos basicamente por discos duplos, atualmente substituídos por hastes rompedoras.

Um fator importante na operação de semeadura é a velocidade de deslocamento do conjunto tratorsemeadora, a qual influencia diversos aspectos, entre eles o consumo de combustível (FURLANI; LOPES; SILVA, 2005), a capacidade operacional (BRANQUINHO et al., 2004) e a qualidade de semeadura (DIAS et al., 2009; MELLO et al., 2007).

De acordo com American Society of Agricultural Engineers (1999) a força de tração necessária para a operação de semeadoras de precisão, na direção horizontal do deslocamento, já incluída a resistência ao rolamento da máquina, com bom leito de semeadura, varia de $900 \mathrm{~N} \pm 25 \%$ por linha (somente semeadura) e de $3.400 \mathrm{~N} \pm 35 \%$ por linha (semeadura, adubação e herbicida).

Silveira et al. (2005a), Mahl et al. (2004) e Furlani et al. (2008) observaram incremento na força de tração e potência na barra com o aumento da velocidade de operação do conjunto mecanizado. Por outro lado, Trintin, Pinheiro Neto e Bortolotto (2005) não observaram o efeito da velocidade sobre as forças de tração média e máxima; entretanto, verificaram o aumento do consumo horário de combustível e potências média e máxima.

Silveira, Gabriel Filho e Secco (2005b), analisando a demanda de potência de uma semeadoraadubadora na cultura do milho em solo argiloso, encontraram, com o aumento da velocidade de 5,28 para $7,08 \mathrm{~km} \mathrm{~h}^{-1}$, a uma mesma profundidade de trabalho, aumento na demanda de potência de $21,25 \%$ na profundidade de $6,8 \mathrm{~cm} \mathrm{e} 45,69 \%$ na de $8,1 \mathrm{~cm}$.

Dentro do contexto apresentado, este trabalho tem como objetivo avaliar a demanda energética de um conjunto trator-semeadora-adubadora em sistema de plantio direto, em diferentes velocidades de deslocamento, obtidas em função do escalonamento de marchas do trator e de rotações no eixo do motor.

\section{MATERIAL E MÉTODOS}

O experimento foi conduzido no Campo Experimental da Fundação Assis Gurgacz, em Cascavel-PR, em Latossolo Vermelho distroférrico de textura muito argilosa $(6,8 \%$ de areia; $17,80 \%$ de silte e $75,40 \%$ de argila), com altitude de $760 \mathrm{~m}$. O delineamento experimental foi em blocos ao acaso com quatro repetições em arranjo fatorial $4 \times 3$, com 12 tratamentos, constituídos de quatro velocidades de deslocamento $\left(3,5 ; 4,0 ; 5,5\right.$ e 7,0 $\left.\mathrm{km} \mathrm{h}^{-1}\right)$ obtidas em função dos escalonamentos de marchas e de três rotações do motor do trator $(1.500 ; 1.900$ e $2.100 \mathrm{rpm})$, totalizando 48 parcelas, com 5,0 m de largura por $30,0 \mathrm{~m}$ de comprimento.

$\mathrm{O}$ experimento foi conduzido em área cultivada no sistema de plantio direto há 8 anos, a qual apresentava as seguintes características: 2,41 tha $^{-1}$ de biomassa; teores médios de água e de massa específica no solo na profundidade de $0-0,10 \mathrm{~m}$, eram de $0,32 \mathrm{~kg} \mathrm{~kg}^{-1}$ e $1,05 \mathrm{Mg} \mathrm{m}^{-3}$, respectivamente, e na profundidade de $0,10-0,20 \mathrm{~m}$, os valores médios eram de $0,26 \mathrm{~kg} \mathrm{~kg}^{-1}$ e $1,11 \mathrm{Mg} \mathrm{m}^{-3}$. O maior valor encontrado para a resistência mecânica do solo à penetração na área experimental foi de $1,36 \mathrm{MPa}$ na profundidade de $0-0,10 \mathrm{~m}$.

Utilizou-se uma semeadora-adubadora marca Tatu Marchesan PST $^{3}$ de arrasto, com seis linhas de semeadura, dotada de disco de corte para palhada de 18 " $(45,7 \mathrm{~cm})$, haste sulcadora para adubo com $2,7 \mathrm{~cm}$ de espessura da ponteira e ângulo de ataque de $20^{\circ}$ e mecanismos sulcadores de discos duplos de 15 " $(38,1 \mathrm{~cm})$ para deposição de sementes. Para tracionar a semeadora foi utilizado um trator marca FORD, modelo 7630, 4 x 2 TDA, potência de 75,8 kW $(103 \mathrm{cv})$ no motor a $2.100 \mathrm{rpm}$ e massa de $6.196 \mathrm{~kg}$ (lastro máximo). A semeadora foi regulada visando a distribuição de 5,9 sementes por metro linear a uma profundidade média de $5,0 \mathrm{~cm}$, enquanto que o adubo foi depositado a uma profundidade média de $10 \mathrm{~cm}$.

Um sistema de aquisição de dados Datalogger CR23X da Campbell Scientific foi utilizado para armazenare gravarcontinuamente os sinais gerados pelos 
transdutores instalados no conjunto motomecanizado. Foram monitorados a força média de tração na barra requerida pela semeadora-adubadora, a velocidade de deslocamento e o consumo de combustível. Para medir o requerimento de força de tração utilizou-se uma célula de carga marca SODMEX, modelo N400, com sensibilidade de $2,156 \mathrm{mV} \mathrm{V}^{-1}$, acoplada entre o trator e a semeadora. A força de tração média foi determinada pela equação 1 .

$$
F_{m}=\frac{\sum_{i=1}^{n} F i}{n} \times 0,0098
$$

Em que, $\mathrm{F}_{\mathrm{m}}$ - força de tração média $(\mathrm{kN}) ; \mathrm{F}_{\mathrm{i}}$ - força de tração instantânea (kgf); n - número de dados registrados; 0,0098 - fator de conversão para kN.

A velocidade de deslocamento foi monitorada por uma unidade de radar marca Dickey-John, modelo DjRVS, com erro menor que $\pm 3 \%$ para velocidades de 3,2 a $7,08 \mathrm{~km} \mathrm{~h}^{-1}$. Para a determinação da rotação do motor, utilizou-se um sensor ótico infravermelho e uma roda dentada com 60 dentes acoplada à tomada de potência (TDP) do trator. Conhecendo a relação de transmissão entre a rotação do eixo do motor e a rotação da TDP e o número de impulsos gerados pela roda dentada acoplada à TDP, determinou-se então, a rotação do motor. A potência média requerida na barra de tração foi determinada utilizando a equação 2 .

$P_{b}=F_{m} x V_{m}$

Em que, $P_{b}$ - potência média na barra de tração $(\mathrm{kW})$; $V_{m}$ - velocidade média de deslocamento $\left(\mathrm{m} \mathrm{s}^{-1}\right)$.

O consumo de combustível foi determinado utilizando-se dois medidores volumétricosFLOWMATE M-III, modelo LSN40. Um dos medidores foi instalado na linha de alimentação do combustível antes dos filtros secundários, e o outro medidor quantificou o volume de combustível, que retornou dos bicos injetores. $\mathrm{O}$ consumo específico de combustível foi determinado utilizando-se a equação 3 .

$$
C e=\frac{C h}{P b} \times d
$$

Em que, $C e$ - consumo específico de combustível $\left(\mathrm{g} \mathrm{kW}^{-1} \mathrm{~h}^{-1}\right)$; $C h$ - consumo horário de combustível $\left(\mathrm{L} \mathrm{h}^{-1}\right)$; $P b=$ potência na barra de tração $(\mathrm{kW}) ; d$ - densidade do combustível $\left(\mathrm{g} \mathrm{L}^{-1}\right)$.
O consumo de combustível por área mobilizada de solo foi calculado pela equação 4 .

$$
C a_{m}=\frac{C e}{A_{m}}
$$

Em que, $C a_{m}$ - consumo de combustível por área mobilizada $\left(\mathrm{kg} \mathrm{kW}^{-1} \mathrm{~h}^{-1} \mathrm{~m}^{-2}\right) ; A_{m}=$ área de solo mobilizada $\left(\mathrm{m}^{2}\right)$.

A obtenção dos dados de profundidades do sulco se deu com a inserção da régua graduada em centímetros, com resolução de $1,0 \mathrm{~mm}$, dentro do sulco de semeadura, onde foi realizada a leitura da profundidade do fundo do sulco à superfície do solo, sendo realizada 15 leituras por linha de semeadura. Para a determinação da área de solo mobilizada utilizou-se um perfilômetro, construído em alumínio, com réguas verticais graduadas em centímetros dispostas a cada 2 $\mathrm{cm}$ no sentido transversal à linha de semeadura, sendo realizada quatro repetições por unidade experimental.

Os resultados foram submetidos à análise de variância e quando a interação entre os fatores velocidades de operação e rotações do motor foi significativa, utilizou-se a análise de regressão. A análise estatística foi realizada por meio do software Sistema para Análises Estatísticas 9.1 (2007).

\section{RESULTADOS E DISCUSSÃO}

Nas Tabelas 1 e 2 são apresentados os resumos das análises de variância da demanda energética da semeadora-adubadora em diferentes velocidades de operação e rotações do motor. Com esses resultados, realizou-se as análises de regressão por meio do teste "t" de Student a 5\% de probabilidade, o qual evidenciou que, a rotação do motor influenciou significativamente apenas os consumos horário e específico de combustível, enquanto que a velocidade de operação apresentou significâncias sobre os coeficientes da regressão dos demais parâmetros analisados.

\section{Profundidade do sulco para deposição do adubo}

Na Figura 1, observa-se que a profundidade de sulco teve comportamento linear decrescente, com coeficiente de determinação de 0,94 . Foi verificado para a maior velocidade $\left(7,0 \mathrm{~km} \mathrm{~h}^{-1}\right)$ a menor profundidade do sulco $(0,093 \mathrm{~m})$ e para a menor velocidade $\left(3,5 \mathrm{~km} \mathrm{~h}^{-1}\right)$ a maior profundidade $(0,11 \mathrm{~m})$. Resultados semelhantes foram encontrados por Casão Júnior et al. (2000) e Mahl et al. (2004) quando constataram maiores profundidades do sulco nas menores velocidades de deslocamento. 
Tabela 1 - Resumo da análise de variância da demanda energética da semeadora, submetida a diferentes velocidades de operação e rotações do motor

\begin{tabular}{|c|c|c|c|c|c|c|}
\hline \multirow{2}{*}{ F.V. } & \multicolumn{6}{|c|}{ QUADRADO MÉDIO } \\
\hline & GL & Ps & Am & $\mathrm{Fm}$ & $\mathrm{Pm}$ & P/Linha \\
\hline Bloco & 3 & $0,00001^{\mathrm{ns}}$ & $0,000001^{\mathrm{ns}}$ & $0,0327^{\mathrm{ns}}$ & $0,2452^{\mathrm{ns}}$ & $0,00681^{\mathrm{ns}}$ \\
\hline Vel & 3 & $0,0009 * *$ & $0,00002 * *$ & $3,5125^{* *}$ & $510,52 * *$ & $14,1812 * *$ \\
\hline Rot & 2 & $0,00003^{\mathrm{ns}}$ & $0,000007^{*}$ & $0,2822^{\mathrm{ns}}$ & $1,3991 *$ & $0,0388^{*}$ \\
\hline Rot x Vel & 6 & $0,00006^{*}$ & $0,00001 * *$ & $0,1682^{\mathrm{ns}}$ & $10,0724 * *$ & $0,2797 * *$ \\
\hline Resíduo & 33 & 0,00002 & 0,000002 & 0,1598 & 0,3690 & 0,0102 \\
\hline $\mathrm{CV}(\%)$ & & 4,48 & 17,98 & 2,64 & 3,02 & 2,02 \\
\hline
\end{tabular}

FV - Fontes de variação; VEL - Velocidades de operação; ROT - Rotações do Motor; Ps - Profundidade de sulco do adubo (m); Am - Área de solo mobilizada $\left(\mathrm{m}^{2}\right)$; Fm - Força média na barra de tração $(\mathrm{kN})$; Pm - Potência média na barra de tração (kW); P/linha - Potência média por linha de semeadura $\left(\mathrm{kW}\right.$ linha $\left.{ }^{-1}\right){ }^{\text {ns }}$ - não significativo, ${ }^{*}$ - significativo a $5 \%$ pelo teste $\mathrm{F}$

Tabela 2 - Resumo da análise de variância da demanda energética solicitada por uma semeadora, submetida a diferentes velocidades de operação e rotações do motor

\begin{tabular}{lcccccc}
\hline \multirow{2}{*}{ F.V. } & \multicolumn{5}{c}{ QUADRADO MÉDIO } \\
\cline { 2 - 7 } & GL & P/Ps & P/Am & Ch & Ce & Ce/Am \\
\hline Bloco & 3 & $4,8495^{\text {ns }}$ & $43693,19^{\text {ns }}$ & $0,0931^{*}$ & $130,86^{\text {ns }}$ & $93,9737^{\text {ns }}$ \\
Vel & 3 & $2234,71^{* *}$ & $1299178^{* *}$ & $52,9921^{* *}$ & $56885,54^{* *}$ & $5594,88^{* *}$ \\
Rot & 2 & $12,4768^{\text {ns }}$ & $1055119^{* *}$ & $42,9459^{* *}$ & $115812,2^{* *}$ & $1380,75^{* *}$ \\
Rot x Vel & 6 & $26,1714^{* *}$ & $1844409^{* *}$ & $0,4755^{* *}$ & $9405,12^{* *}$ & $725,76^{*}$ \\
Resíduo & 33 & 5,5029 & 221375,4 & 0,0771 & 198,53 & 247,29 \\
CV $(\%)$ & & 3,02 & 17,99 & 2,51 & 2,95 & 24,18 \\
\hline
\end{tabular}

FV - Fontes de variação; VEL - Velocidades de operação; ROT - Rotações do Motor; P/Ps - Potência por profundidade de sulco $\left(\mathrm{kW} \mathrm{m}^{-1}\right) ; \mathrm{P} / \mathrm{Am}$ Potência por área de solo mobilizada $\left(\mathrm{kW} \mathrm{m}^{-2}\right)$; Ch - Consumo Horário de combustível $\left(\mathrm{L} \mathrm{h}^{-1}\right) ; \mathrm{Ce}$ - Consumo específico de combustível $\left(\mathrm{g} \mathrm{kW}^{-1} \mathrm{~h}^{-1}\right)$; Ce/Am - Consumo específico por área de solo mobilizada $\left(\mathrm{g} \mathrm{kw}^{-1} \mathrm{~m}^{-2}\right)$; ${ }^{\mathrm{ns}}$ - não significativo, $*$ - significativo a $5 \%$ pelo teste $\mathrm{F}$

Figura 1 - Profundidade do sulco do adubo em função da velocidade de operação do conjunto mecanizado

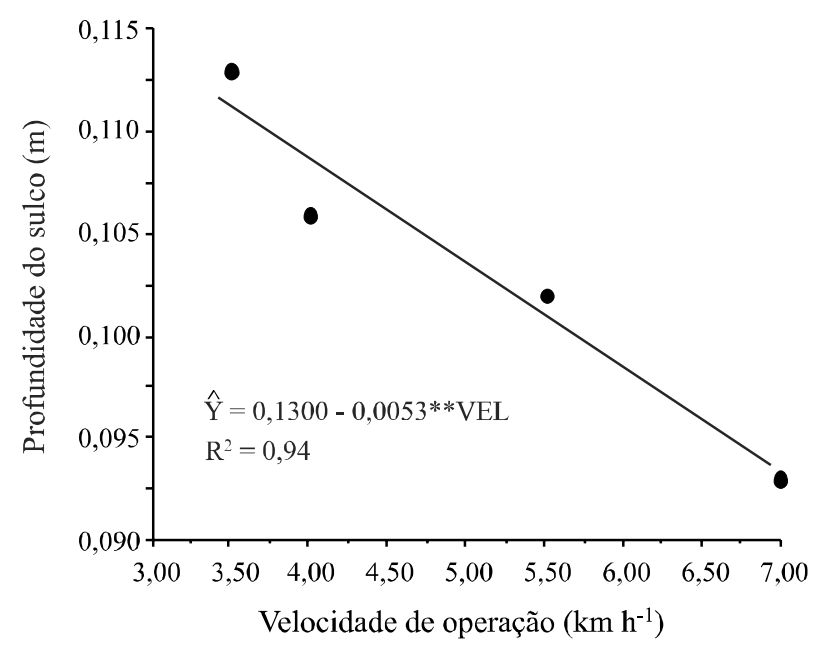

Já Modolo et al. (2004) observaram variação na profundidade de semeadura conforme aumento da velocidade de deslocamento em uma das duas semeadorasadubadoras estudadas. A profundidade elevou-se $24,2 \%$ quando a velocidade de deslocamento passou de 5,2 para $8,4 \mathrm{~km} \mathrm{~h}^{-1}$, indo contra o presente trabalho. Enquanto Camilo et al. (2004), estudando mecanismos rompedores do solo e velocidades de semeadura não observaram influência da velocidade de semeadura sobre a profundidade de deposição de sementes.

\section{Área mobilizada de solo}

Observa-se na Figura 2 que o modelo ajustado apresentou comportamento linear crescente com coeficiente de determinação de 0,92 , e que, para cada unidade de aumento da velocidade de operação, tem-se um acréscimo na área mobilizada de solo de $0,0008 \mathrm{~m}^{2}$. 
Figura 2 - Área mobilizada de solo, em função da velocidade de operação do conjunto mecanizado

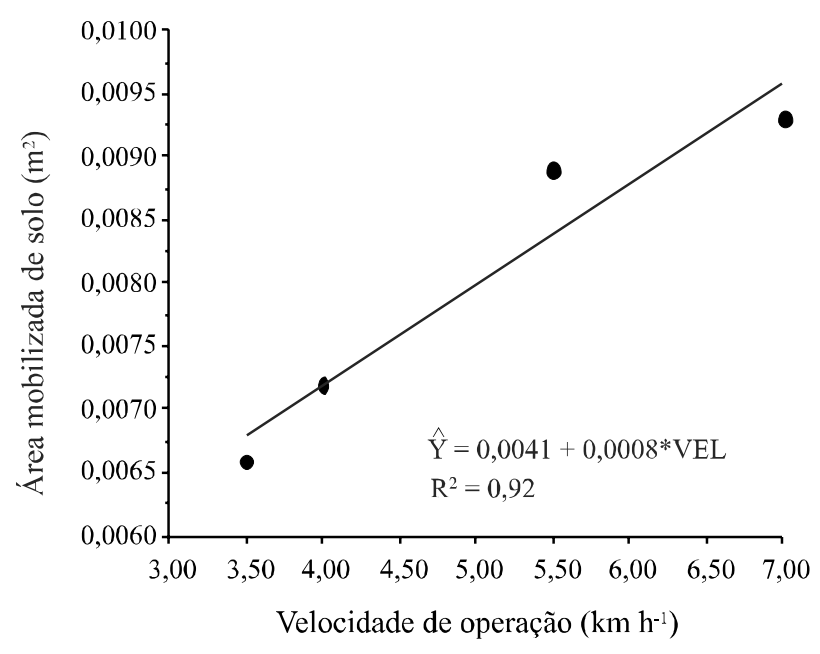

Cepik, Trein e Levien (2005) trabalhando com solos em diferentes teores de água, profundidades de semeadura e duas velocidades, observaram que, ao aumentar a velocidade de semeadura de 4,5 para $6,5 \mathrm{~km} \mathrm{~h}^{-1}$ o volume de solo mobilizado elevou-se em $12 \%$. No presente trabalho, quando a velocidade passou de 3,5 para $7,0 \mathrm{~km} \mathrm{~h}^{-1}$, houve um incremento de $41 \%$ na área mobilizada de solo, por linha de semeadura. No entanto, Silva et al. (2001), trabalhando em solo argiloso não verificaram esse comportamento na área mobilizada de solo na semeadura do milho quando aumentaram a velocidade de operação.

\section{Força média requerida na barra de tração}

Nota-se na Figura 3 que quando a velocidade aumentou de 3,5 para $7,0 \mathrm{~km} \mathrm{~h}^{-1}$ houve redução de $9 \%$ da força requerida, o que, para efeito de cálculo no dimensionamento do conjunto, deve ser considerado. Este resultado pode estar atribuído à menor profundidade de sulco encontrada na maior velocidade de trabalho (Figura 1).

A exigência de força em semeadoras é função de diversos fatores, tais como: tipo de solo e cobertura, mecanismos sulcadores, tamanho da máquina, profundidade de semeadura/adubação, velocidade de semeadura, teor de água e preparo do solo. Nesse sentido, Furlani et al. (2007), também encontraram redução na força requerida na barra de tração em função do aumento da velocidade de trabalho quando avaliaram o desempenho de uma semadora-adubadora equipada com sulcador tipo haste em diferentes manejos de cobertura e velocidades de deslocamento em Latossolo Vermelho eutrópico típico. No entanto, Bortolotto, Pinheiro Neto e Bortolotto (2006) avaliando a demanda energética de uma semeadoraadubadora em diferentes velocidades de deslocamento e condições de cobertura do solo em sistema de plantio direto da cultura da soja em Latossolo Vermelho distrófico constataram aumento da força na barra de tração de 2,5\% quando a velocidade de operação passou de 4,7 para $7,2 \mathrm{~km} \mathrm{~h}^{-1}$. Por outro lado, Modolo et al. (2004) avaliando o desempenho de duas semeadoras-adubadoras equipadas com sulcadores do tipo guilhotinha e disco duplo defasados em duas velocidades de deslocamento no mesmo solo em que este trabalho foi realizado, não encontraram efeitos do aumento da velocidade de trabalho sobre os valores médios da força de tração na barra.

Figura 3 - Força requerida na barra de tração em função da velocidade de operação do conjunto mecanizado

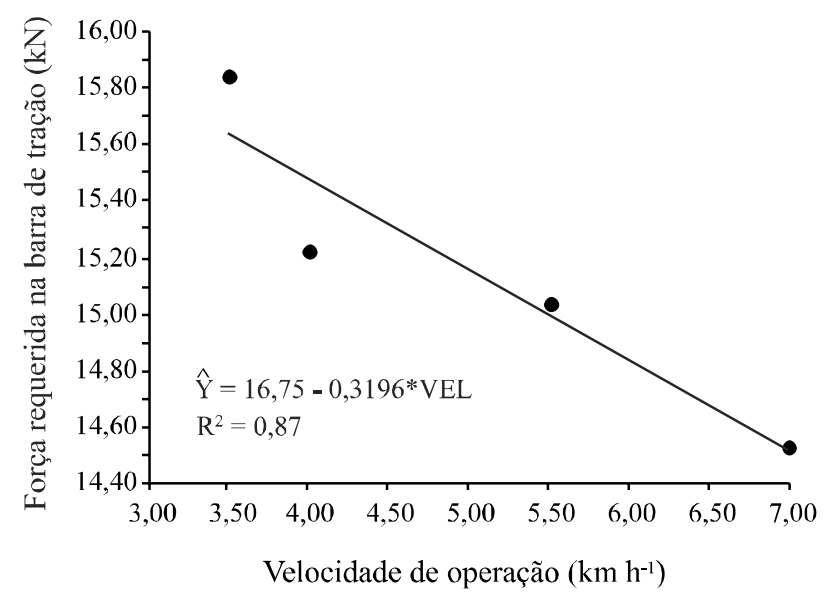

\section{Potência média na barra de tração}

Em relação à potência média requerida na barra de tração, verifica-se na Figura 4 que as duas variáveis se movem na mesma direção, com forte correlação, e que, a cada aumento na velocidade de operação, ocorre um incremento de $4,11 \mathrm{~kW}$ na demanda de potência requerida na barra de tração. Este aumento na demanda de potência pelo conjunto mecanizado, acarreta em redução do torque do motor, surgindo com o decorrer do tempo, perdas de rendimento do motor devido a sobrecargas e, conseqüentemente, perdas de tração, além de ocasionar aumento no consumo específico de combustível.

Os valores médios encontrados para a potência média na barra de tração nas velocidades de deslocamento de 3,$5 ; 4,0 ; 5,5$ e $7,0 \mathrm{~km} \mathrm{~h}^{-1}$ foram de 13,$95 ; 16,00 ; 22,17$ e $28,33 \mathrm{~kW}$, respectivamente.

$\mathrm{O}$ aumento na velocidade de 3,5 para $7,0 \mathrm{~km} \mathrm{~h}^{-1}$ provocou incremento na demanda de potência de $102,89 \%$. Resultados semelhantes foram obtidos por Bortolotto, 
Pinheiro Neto e Bortolotto (2005), Casão Júnior e Siqueira (2003); Mahl et al. (2004), Modolo et al. (2005) e Silveira, Gabriel Filho e Secco (2005b).

Figura 4 - Estimativa da potência requerida na barra de tração em função da velocidade de operação do conjunto mecanizado

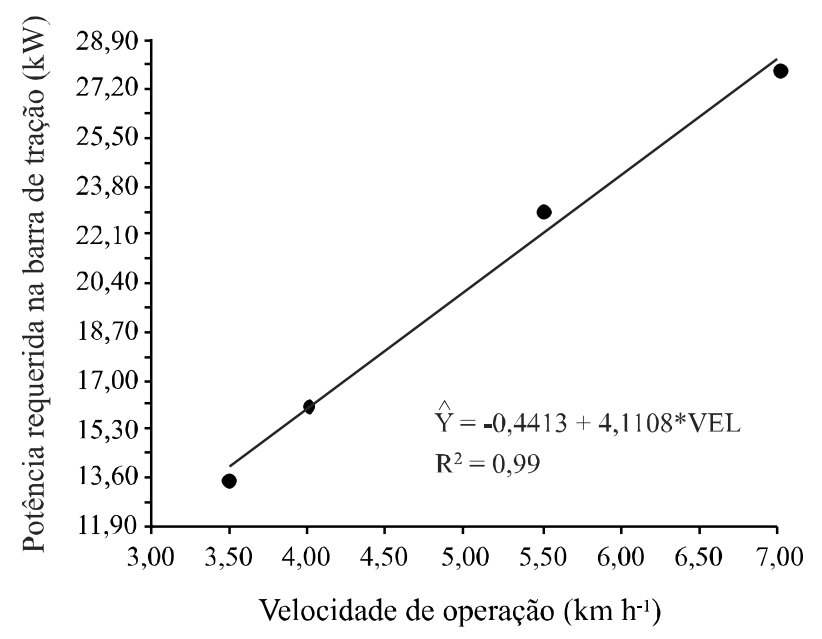

\section{Potência na barra de tração por linha de semeadura}

Para a potência requerida por linha de semeadura (Figura 5), verifica-se que a cada unidade de variação na velocidade de operação há acréscimo de $0,68 \mathrm{~kW}$ na potência na barra por linha de semeadura. Os valores médios obtidos da variável em estudo foram 2,32; 2,67; 3,69 e 4,72 kW por linha de semeadura, da menor para a maior velocidade de operação, representando um aumento de $104,74 \%$ quando a velocidade passou de 3,5 para 7,0 $\mathrm{km} \mathrm{h}^{-1}$.

Figura 5 - Estimativa da potência requerida na barra de tração por linha de semeadura, em função da velocidade de operação do conjunto mecanizado

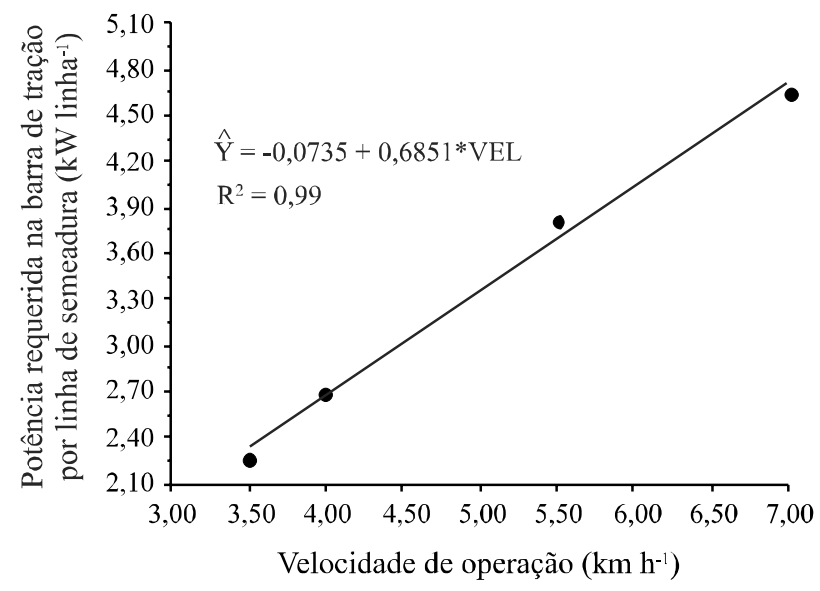

\section{Potência na barra de tração por profundidade do sulco}

Na Figura 6 verifica-se que a cada unidade de variação na velocidade de operação há acréscimo de $8,63 \mathrm{~kW} \mathrm{~m}^{-1}$ na potência requerida na barra de tração por profundidade do sulco.

Os valores médios encontrados neste trabalho com as velocidades de deslocamentos de 3,5; 4,0; 5,5 e 7,0 $\mathrm{km} \mathrm{h}^{-1}$, foram de 20,37; 24,68; 37,62 e 50,56 $\mathrm{kW} \mathrm{m}^{-1}$, respectivamente, e o aumento na velocidade de operação de 3,5 para 7,0 $\mathrm{km} \mathrm{h}^{-1}$ proporcionou aumento de $148,21 \%$ no requerimento de potência na barra de tração por profundidade do sulco.

Figura 6 - Estimativa da potência requerida na barra de tração por profundidade do sulco, em função da velocidade de operação do conjunto mecanizado

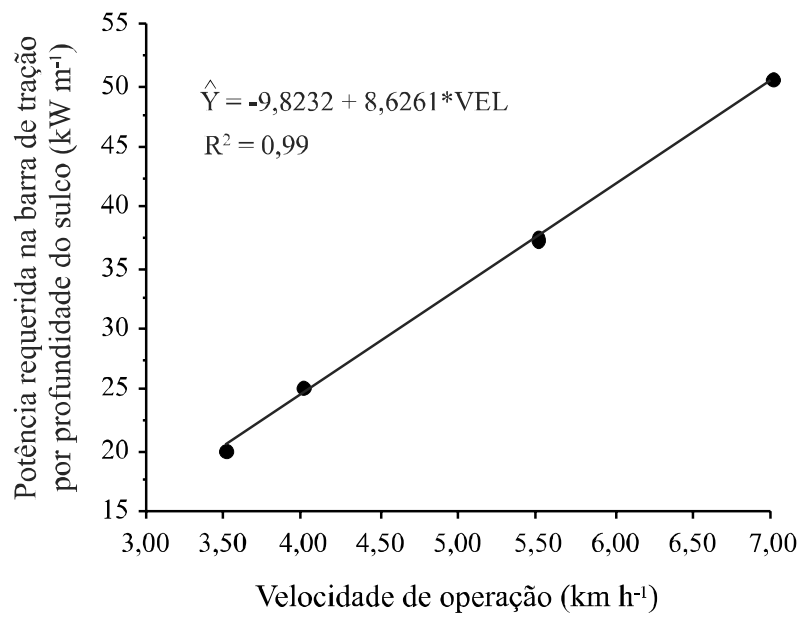

\section{Potência requerida na barra de tração por área mobilizada de solo}

Na Figura 7, observa-se que a cada incremento na variação da velocidade de operação, ocorre aumento na potência requerida na barra de tração por área mobilizada de solo de $204,32 \mathrm{~kW} \mathrm{~m}^{-2}$. Os valores médios da potência média na barra de tração por área mobilizada de solo, nas velocidades de deslocamento estudadas, foram de $2.308,63 ; 2.410,79 ; 2.717,27$ e $3.023,75 \mathrm{~kW} \mathrm{~m}^{-2}$, nas respectivas velocidades de 3,$5 ; 4,0 ; 5,5$ e 7,0 $\mathrm{km} \mathrm{h}^{-1}$, um aumento da menor para a maior velocidade de $30,98 \%$.

\section{Consumo horário de combustível}

O modelo de superfície estimado usando-se as médias dos tratamentos, com relação à variável consumo horário de combustível em função da velocidade de operação e da rotação no eixo do motor, é apresentado 
Figura 7 - Estimativa da potência requerida na barra de tração por área mobilizada de solo, função da velocidade de operação do conjunto mecanizado

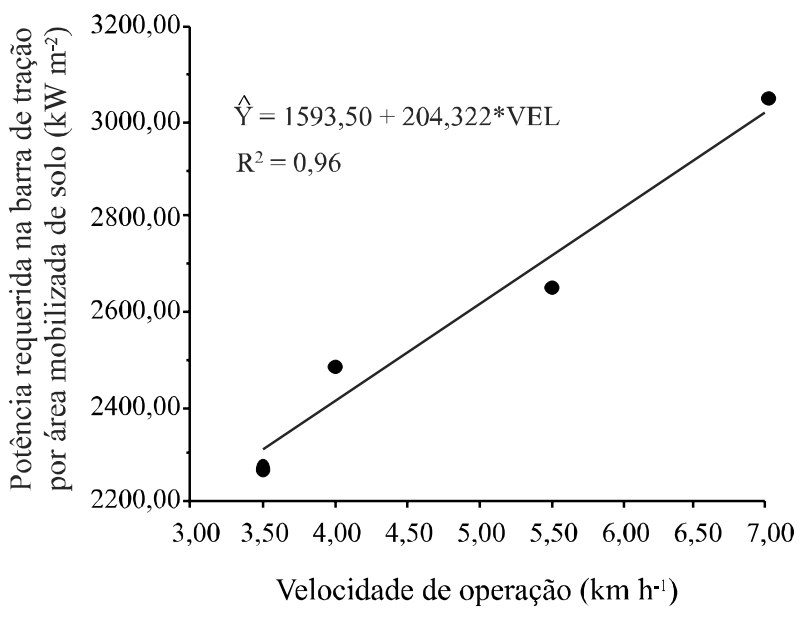

pela equação 5, e a superfície de resposta ajustada aos dados de consumo horário de combustível, de acordo com o modelo polinomial de regressão estimado, encontra-se na Figura 8.

$$
\hat{Y}=-5,3302+1,3192 * * V E L+0,0053 * * R O T \quad R^{2}=0,98
$$

Figura 8 - Efeito da velocidade de operação e da rotação no eixo do motor sobre o consumo horário de combustível

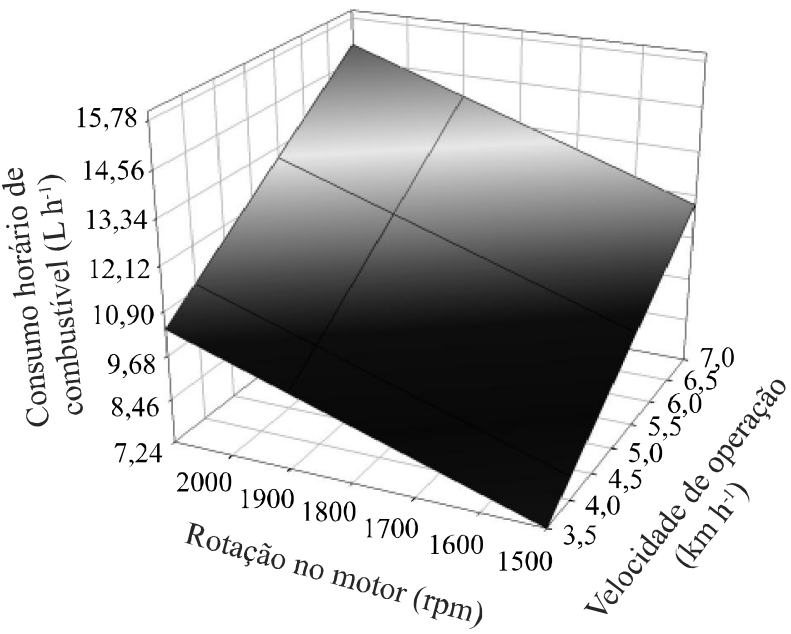

Verifica-se na equação, incrementos no consumo horário de combustível quando da variação da velocidade de operação e da rotação no eixo do motor, ou seja, a cada unidade acrescida na velocidade de operação e na rotação no eixo do motor há um aumento de 1,32 e
$0,0053 \mathrm{~L} \mathrm{~h}^{-1}$, respectivamente. Assim, por essa equação pode-se determinar, considerando o escalonamento de marcha e da rotação no eixo do motor aceitável, aquela que melhor responderá ao menor consumo horário de combustível. Portanto, dentro de uma mesma velocidade de operação e variando a rotação no eixo do motor, têm-se aumentos significativos no consumo horário de combustível, os quais variam de 7 a 44\%, da menor para a maior rotação no eixo do motor. Silva et al. (2003) alternando a rotação no eixo do motor, encontraram aumento no consumo horário de combustível de $71 \%$, com uma única marcha do trator na operação de semeadura do milho.

Verifica-se ainda, que os menores índices de consumo horário de combustível foram encontrados na velocidade de $3,5 \mathrm{~km} \mathrm{~h}^{-1}$, nas rotações de $1.500,1.900$ e $2100 \mathrm{rpm}$, a qual foi aumentando com o incremento da velocidade, nas respectivas rotações do motor.

Nas operações de semeadura, na maioria das vezes os tratoristas utilizam acelerações máximas e marchas inadequadas, preocupando-se pouco com o consumo de combustível, que deve ser considerado. Dentro desse contexto, pode-se afirmar, considerandose a equação e o gráfico de superfície de resposta, que a mudança na rotação de 2.100 para $1.500 \mathrm{rpm}$, nesse trabalho, nas velocidades de 3,5;4,0;5,5 e $7,0 \mathrm{~km} \mathrm{~h}^{-1}$, proporciona redução no consumo horário de combustível de $31 ; 29 ; 24$ e $21 \%$, nas respectivas velocidades avaliadas. Entretanto, deve-se considerar que caso haja acréscimo na demanda de potência quando se trabalha com o motor em rotações próximas a rotação de torque máximo, que segundo Almeida, Tavares-Silva e Silva (2010) está próxima de 1.500 rpm, tanto a rotação quanto a reserva de torque do motor irão diminuir, ocasionando perdas de rendimento, aumento no consumo de combustível e até o desgaste do motor.

\section{Consumo específico de combustível}

O modelo de superfície estimado, usando-se as médias dos tratamentos da variável consumo específico de combustível em função da velocidade de operação e da rotação no eixo do motor é apresentado na equação 6. Verifica-se que o aumento de cada unidade na velocidade de operação ocorre um decréscimo de $42,63 \mathrm{~g} \mathrm{~kW}^{-1} \mathrm{~h}^{-1}$ no consumo específico de combustível e, aumento da mesma ordem, na rotação no eixo do motor, ocorre acréscimo no consumo específico de combustível, na ordem de $0,28 \mathrm{~g} \mathrm{~kW}^{-1} \mathrm{~h}^{-1}$.

A superfície de resposta ajustada aos dados de consumo específico de combustível, de acordo com o modelo polinomial de regressão estimado, encontrase na Figura 9, em que se observa que o aumento na 
velocidade de 3,5 para 7,0 $\mathrm{km} \mathrm{h}^{-1}$, em uma mesma rotação, acarreta redução no consumo específico de combustível, e aumentando a rotação no eixo do motor em uma mesma velocidade de operação ocorre aumento no consumo específico. Esses resultados corroboram com os encontrados por Cortez et al. (2007) e Mahl et al. (2004) em que os menores valores de consumo específico de combustível são obtidos nas maiores velocidades.

$\hat{Y}=181,3930-42,348 * * V E L+0,2779 * * R O T R^{2}=0,86$

Figura 9 - Efeito da velocidade de operação e da rotação no eixo do motor sobre o consumo específico de combustível

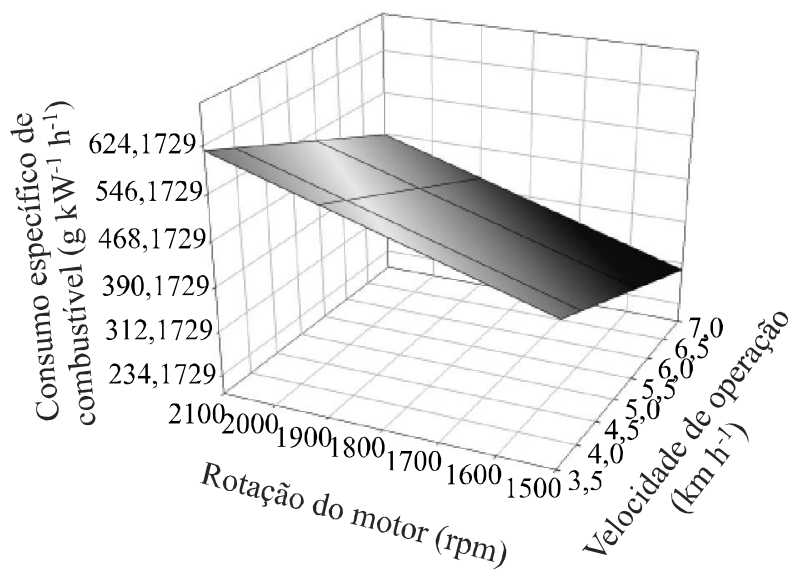

Fica evidenciado a possibilidade de trabalhar com rotações menores e velocidades adequadas em função do escalonamento de marcha com o propósito de se utilizar eficientemente o combustível nas operações de semeadura, desde que não haja sobrecarga a ponto de reduzir a reserva de torque do motor.

\section{Consumo específico de combustível por área mobilizada de solo}

Na Figura 10 são apresentados o gráfico e a equação de regressão da variável consumo específico de combustível por área mobilizada de solo. O modelo encontrado apresentou comportamento linear decrescente, com coeficiente de correlação de 0,90. A cada incremento na variação da velocidade de operação ocorre decréscimo no consumo de combustível por área mobilizada de solo de $12,94 \mathrm{~g} \mathrm{~kW}^{-1} \mathrm{~h}^{-1} \mathrm{~m}^{-2}$. Os maiores valores de consumo de combustível por área mobilizada de solo foram encontrados na menor velocidade de operação.
Figura 10 - Estimativa do consumo específico de combustível por área mobilizada de solo, em função da velocidade de operação do conjunto mecanizado

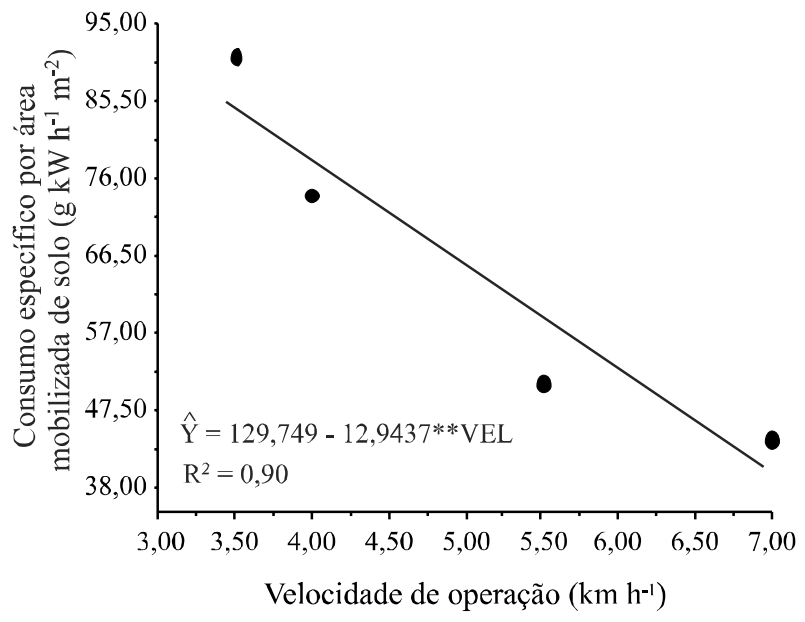

\section{CONCLUSÕES}

1. A força média na barra de tração diminuiu com o aumento da velocidade, enquanto que a potência média, por linha de semeadura, por profundidade do sulco e por área mobilizada aumentou como o aumento da velocidade de operação do conjunto mecanizado.

2.O consumo horário de combustível foi elevado com o aumento da velocidade de operação e da rotação do motor, sendo menor na rotação de $1.500 \mathrm{rpm}$. O menor consumo específico de combustível foi obtido na maior velocidade de operação e na menor rotação do motor.

\section{REFERÊNCIAS}

ALMEIDA, R. A. S. de.; TAVARES-SILVA, C. A.; SILVA, S. de L. Desempenho energético de um conjunto trator-semeadora em função do escalonamento de marchas e rotações do motor. Revista Agrarian, v. 03, n. 07, p. 63-70, 2010.

AMERICAN SOCIETY OF AGRICULTURAL ENGINEERS. Agricultural machinery management. In: ASAE standards 1999: standards engineering practices data. San Joseph, 1999. p. 359-66.

BORTOLOTTO, V. C.; PINHEIRO NETO, R.; BORTOLOTTO, M. C. Demanda energética de uma semeadora-adubadora sob diferentes velocidades de deslocamento e tipos de cobertura vegetal no plantio direto da soja. Acta Scientiarum Agronomy, v. 27, n. 02, p. 357-362, 2005.

BORTOLOTTO, V. C.; PINHEIRO NETO, R.; BORTOLOTTO, M. C. Demanda energética de uma semeadora-adubadora para soja sob diferentes velocidades de deslocamento e coberturas do solo. Revista Engenharia Agrícola, v. 26, n. 01, p. 122-130, 2006. 
BRANQUINHO, K. B. et al. Desempenho de uma semeadoraadubadora direta, em função da velocidade de deslocamento e do tipo de manejo da biomassa da cultura de cobertura do solo. Revista Engenharia Agrícola, v. 24, n. 02, p. 374-380, 2004.

CAMILO, A. J. et al. Influência de mecanismos rompedores e velocidades de trabalho no desempenho de uma semeadoraadubadora de plantio direto do feijão. Engenharia na Agricultura, v. 12, n. 03, p. 203-211, 2004.

CASÃO JÚNIOR, R. et al. Desempenho da semeadoraadubadora MAGNUM 2850 em plantio direto no basalto paranaense. Pesquisa Agropecuária Brasileira, v. 35, n. 03, p. 523-553, 2000.

CASÃO JÚNIOR, R.; SIQUEIRA, R. Resultados das avaliações do desempenho de semadoras-adubadoras diretas na Costa Oeste Paranaense. Londrina: IAPAR, 2003, 132 p.

CEPIK, C. T. C.; TREIN, C. R.; LEVIEN, R. Força de tração e volume de solo mobilizado por haste sulcadora em semeadura direta sobre campo nativo, em função do teor de água no solo, profundidade e velocidade de operação. Revista Engenharia Agrícola, v. 25, n. 02, p. 447-457, 2005.

CORTEZ, J. W. et al. Consumo de energia na operação de semeadura em plantio direto. In: CONGRESSO BRASILEIRO DE ENGENHARIA AGRÍCOLA, 36. 2007, Bonito. Anais... Bonito: SBEA, 2007, p. 1-4.

DIAS, O. V. et al. Distribuição de sementes de milho e soja em função da velocidade e densidade de semeadura. Ciência Rural, v. 39, n. 06, p. 1721-1728, 2009.

FURLANI, C. E. A.; LOPES, A. SILVA, R. P. Avaliação de semeadora-adubadora de precisão trabalhando em três sistemas de preparo do solo. Revista Engenharia Agrícola, v. 25 , n. 02 , p. $458-464,2005$.

FURLANI, C. E. A. et al. Desempenho operacional de semeadora-adubadora em diferentes manejos da cobertura e da velocidade. Revista Engenharia Agrícola, v. 27, n. 02, p. 456-462, 2007

FURLANI, C. E. A. et al. Semeadora-adubadora: exigências em função do preparo do solo, da pressão de inflação do pneu e da velocidade. Revista Brasileira de Ciência do Solo, v. 32, n. 01, p. 345-352, 2008.
MAHL, D. et al. Demanda energética e eficiência da distribuição de sementes de Milho sob variação de velocidade e condição de solo. Revista Engenharia Agrícola, v. 24, n. 01, p. 150-157, 2004.

MELlO, A. J. R. et al. Produtividade de híbridos de milho em função da velocidade de semeadura. Revista Engenharia Agrícola, v. 27, n. 02, p. 479-486, 2007.

MODOLO, A. J. et al. Avaliação do desempenho de duas semeadoras-adubadoras de precisão em diferentes velocidades. Engenharia na Agricultura, v. 12, n. 04, p. 298-306, 2004.

MODOLO, A. J. et al. Demanda energética solicitada por uma semeadora-adubadora de precisão com diferentes unidades de semeadura. Acta Scientiarum Agronomy, v. 27, n. 03, p. 473-479, 2005.

OLIVEIRA, M. F. B. et al. Mobilização do solo por hastes sulcadoras de semeadoras-adubadoras de plantio direto. In: CONGRESSO BRASILEIRO DE ENGENHARIA AGRÍCOLA, 29., 2000. Goiânia. Anais... Goiânia: SBEA, 2000. p. 01-04.

SILVA, A. R. B. et al. Avaliação de uma semeadora-adubadora de plantio direto em função de diferentes mecanismos sulcadores e velocidades de deslocamento. In: CONGRESSO BRASILEIRO DE ENGENHARIA AGRÍCOLA, 30., 2001. Foz do Iguaçu. Anais... Foz do Iguaçu: SBEA, 2001. p. 01-04.

SILVA, S. L. et al. Redução do consumo de combustível em função da rotação no eixo do motor. In: CONGRESSO BRASILEIRO DE ENGENHARIA AGRÍCOLA, 32., Goiânia. Anais... Goiânia, SBEA, 2003. p. 01-04.

SILVEIRA, J. C. M. et al. Força de tração e potência em duas velocidades de deslocamento e duas profundidades de deposição de sementes. Revista Brasileira de Engenharia Agrícola e Ambiental, v. 9, n. 01, p. 125-128, 2005a.

SILVEIRA, J. C. M.; GABRIEL FILHO, A.; SECCO, D. Demanda de potência e força de tração de uma semeadora na implantação do milho safrinha sob plantio direto. Engenharia na Agricultura, v. 13, n. 04, p. 256-267. 2005b.

SISTEMA para análises estatísticas. Versão 9.1. Viçosa, MG: Fundação Arthur Bernardes/Universidade Federal de Viçosa, 2007.

TRINTIN, C. G.; PINHEIRO NETO, R.; BORTOLOTTO, V. C. Demanda energética solicitada por uma semeadora-adubadora para plantio direto, submetida a três velocidades de operação. Acta Scientiarum Agronomy, v. 27, n. 01, p. 127-31, 2005. 